\title{
Biochemistry in the High School Textbook: A Distance Between Content And Students Reality?
}

\author{
$\underline{\text { Simões-Pires, A. }}{ }^{1}$; Bristot, I.J. ${ }^{1}$; Moreira, J.C.F. ${ }^{1}$ \\ ${ }^{1}$ Departamento de Bioquímica, Instituto de Ciências Básicas da Saúde- \\ Universidade Federal do Rio Grande do Sul, Rio Grande do Sul, Brazil.
}

Several contents have been taught in a decontextualized way within the area of biology, one of these contents is Biochemistry. Biochemistry is one of the most present subjects in the student's daily lives, because it can explain a huge number of processes that happens in their routine. The textbook is the main tool in the Brazilian public high schools classrooms, so a huge number of programs to improve the textbooks were created by the government, like the National Program of the Textbook or PNLD( translated from the Portuguese "Programa Nacional do Livro Didático"). But despite the efforts to improve the textbook, their quality is still questionable, for such reasons like the distance between contents showed in the textbook and student's reality. The main objective of this work is to evaluate how the high school textbooks show the content related to biochemistry and how this content is contextualized in the student's reality. To achieve this goal we analyzed four textbooks that are most frequently used in the schools today and evaluated parameters related with contextualization between the biochemistry content and students daily lives situations. The analysis was done on a qualitative way. We observed a lack of daily examples in the biochemical contents, an excess of scientific terms without clear explanations and also a huge presence of conceptual errors in all four textbooks. The data showed here leads us to conclude that the science's textbooks analyzed in this study are inappropriate to teach biochemistry in an interesting way for the students.

Word Keys: Textbook, Biochemistry, High School.

Supported by: CNPq 
This document was created with Win2PDF available at http://www.win2pdf.com. The unregistered version of Win2PDF is for evaluation or non-commercial use only. This page will not be added after purchasing Win2PDF. 